\section{THREE LECTURES}

oN

\section{THE PRINCIPLE OF LEAST ACTION IN NATURE, ILLUSTRATED BY ANIMAL MECHANICS.}

\section{Delivered at the Royal Institution of Great Britain. BY THE}

REV. SAMUEL HAUGHTON, M.D.Dubl., D.C.L.Oxon., F.R.S., Fellow of Trinity College, Dublin.

LECTURE II.-Tuesday, May 30th, i871. (Concluded.) Geometrical Classification of Muscles found in Animals. - Application of the principle of Least Action to several forms of Muscle, demonstrating the possibility of "predicting" Animal Structures by Mathematical Calculations similar to those used in Astronomy and the other exact Sciences.-Special Illustrations from the Limbs of the Tiger and Wings of the Albatross.

I HAVE selected, in illustration of triangular muscles, the triangular muscles of the fore and hind limbs of the tiger. I have selected the tiger, because he is the strongest and the handsomest animal with which we are acquainted; and strength and beauty, as long as the world lasts, will always command attention and regard. The tiger is stronger than the lion. I should be sorry to disturb the traditions of childhood which have led any one present to regard the lion as the king of the beasts. I am sorry, however, to say that the lion is a humbug. $\mathrm{He}$ has a big mane, and looks grand, but he is very inferior to the tiger. $\mathrm{He}$ is like some human beings $\mathrm{I}$ am acquainted with-there is more in their appearance than you find carried out on intimate acquaintance. My reason for saying that the tiger is stronger than the lion, is a reason that will interest you. I find that the cruel Emperor Titus, A.D. 80, carried the spectacles in Rome so far as to have Bengal tigers imported from India, and compelled to fight the Numidian lions imported from Africa. In his native haunts in India, the Bengal tiger never meets the African lion. The poor Babylonian lion of Asia is a very small animal compared with the African lion; and I would back two Newfoundland dogs to fight him. The tiger sometimes meets this lion in the north of India, and it is well known that he destroys him. The Emperor Titus determined to try whether the Bengal tiger could or could not fight the large and noble African lion. The poet Martial, in his 18th epigram, De Spectaculis, has recorded the fact that tigers and lions fought in the amphitheatre during the reign of Titus, and that the tiger always killed the lion. There are some points of interest in the quotation, which I can verify. Martial describes the tiger as naturally a gentle animal, accustomed, he says, to lick the right hand of the keeper that trusted him ; but when he came to Rome, and, as Martial observes, learned bad manners amongst the civilised Romans, he lost his native gentleness, and acquired a degree of ferocity that he never possessed in his native woods. The words he uses are:

\section{Lambere securi dextram consueta magistri \\ Tigris ab Hyrcano gloria rara jugo \\ Sæva ferum rabidâ laceravit dente leonem : \\ Res nova, non ullis cognita temporibus. \\ Ausa est tale nihil, sylvis dum vixit in altis,}

Post quam inter nos est, plus feritatis habet."

Accidents have happened, also, in some of our English menageries, where the barrier between the cage of the tiger and the lion has broken down, and the animals have fought. The records of all these cases, believe, show that the tiger, if in good condition, invariably kills the lion when compelled to fight. But the best proof I can give you of the superiority of the tiger, is an experience of my own. What we learn for ourselves makes a stronger impression upon us than what we read from books. I have been for many years Secretary of the Zoological Gardens in Dublin, and have had a large number of tigers and lions under my care. Now, it occasionally happens that with such creatures as these, the claws of the fore paw, from want of natural exercise in scratching trees, like cats, grow into the foot, and cause the animal great pain, ultimately producing death by gangrene, unless the claws be removed; therefore it is not an unusual thing to look after a tiger's toilet, and pare the nails for him from time to time; but it is not an operation that is at all so satisfactory in the actual performance as it appears at first sight. I have performed it repeatedly both on tigers and on lions; and I can give you as the result of my experience, that while it requires eight men to hold down a tiger, five men will easily hold the largest lion. This greatly struck me when $I$ ascertained it; and having the opportunity of examining after death my two friends whose nails I cut, $I$ found, in the cross-sections and weights of the muscles, measure- ments and proportions giving the tiger somewhat more than fifty per cent. of strength greater than the lion; which quite confirmed my observation.

But the operation of cutting the tiger's claws was accompanied, in the first instance that I tried it, with some curious incidents that you might like to hear ; in fact, if they had turned out somewhat differently from what they did, I should not have had the honour of delivering this lecture before you to-day. I collected eight men to assist me; we placed a large rope round the tiger's neck with a stop-knot; a certain number of men held this, and the other men held the tiger's claw that was to be cut, with a rope which lifted the wrist off the ground. They were instructed carefully to keep the tiger's foot off the ground, for the tiger knew well what they were about. He watched the opportunity of putting the sore foot on the ground and slapping me with the other foot ; but as long as the sore foot could be kept off the ground and his head against the bars of the cage, he was compelled to press with his

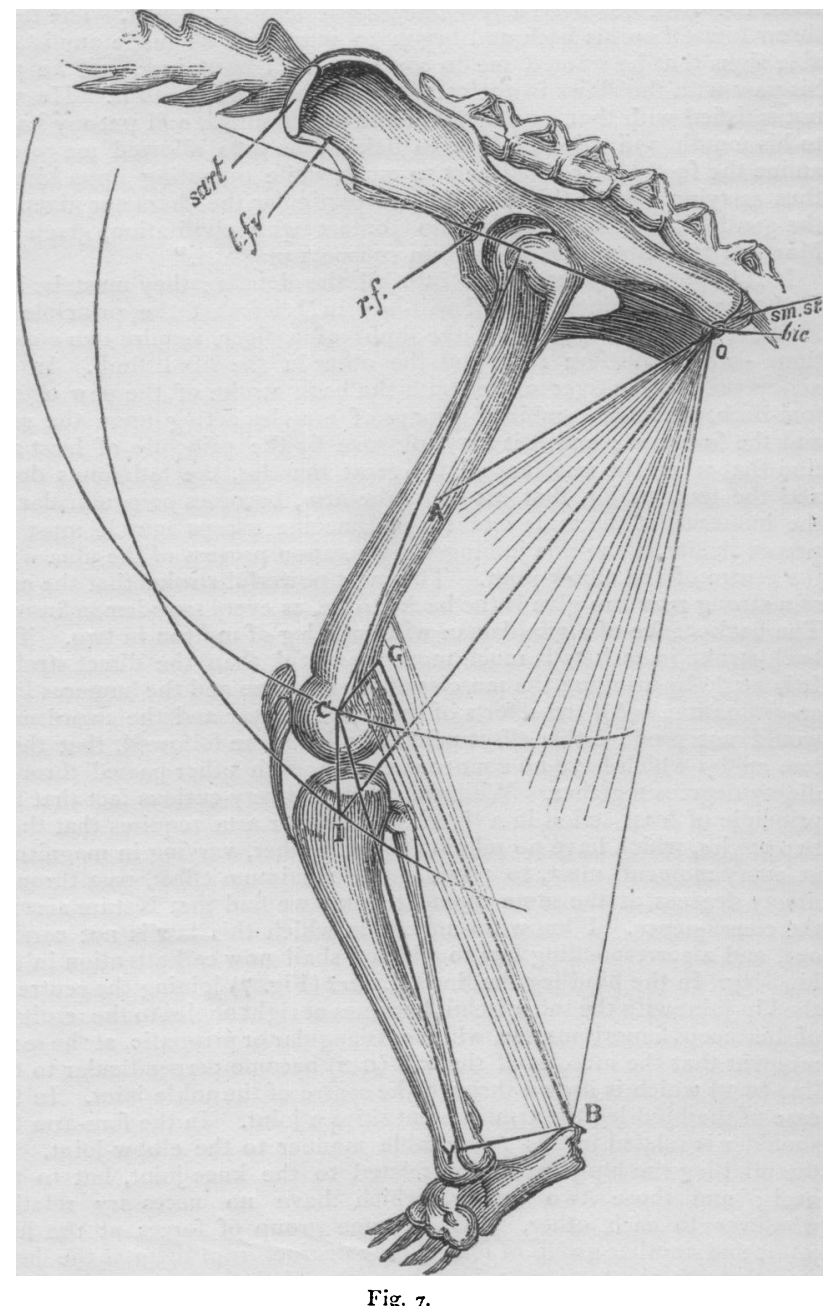

free paw against the ground to save himself from being choked, and I was quite safe. But, unfortunately, in the middle of our proceedings his companion tigress thought she would interfere, and she behaved not unlike the manner in which Jael the wife of Heber or Judith of Bethulia would have done : she came over to see what was going on, put her paw out through the bars, and struck my hat. I was proceeding to cut the tiger's claw when I felt the paw of the tigress at the back of my hat. In a moment, the body of eight men resolved itself into its component parts. Seven of them were cowards; but one was a brave man who had led the celebrated charge of the Grenadier com. pany of the 29th Regiment at the battle of Chillianwallah for the purpose of spiking the guns of the Sikh battery, and was promoted on the field by Lord Gough. He kept his hold of the tiger, but, 
to my astonishment, I saw the seven men rumning like drops of mercury in all directions. The tiger had thrown up the sliding door of the cage, and there was I face to face with him. I saw I was instantly to be killed, but my friend held on by the rope and puzzled the tiger. The animal then backed to the far end of the den, and couched upon its haunches to make a spring at me through the door. I naturally put up my hand and closed the door. The tiger rushed at the bars of the cage and broke his teeth with fury on the bars, because he was prevented from attacking me. I was not to be baffled. I collected the seven cowards again and brought them into the house. I then took the key, locked the door, and put the key in my pocket. "Now, boys", said I, "you ought to be ashamed of yourselves ; you are not worthy of being called Irishmen at all. If any accident happens the tiger will eat me first, key and all, and he will sup off the rest of you at his leisure, so hold on by the ropes." We got the ropes on again, and I cut the tiger's claw ; and thus I developed the greatest possible amount of muscular work that could be got out of seven cowards. After the work was over, a very remarkable scene happened. The tiger threw himself on his back and began to purr, and he made unmistakable signs that he wanted me to come over. I went over, and he put his paw with the claws in against the bars to make me rub it. He was not satisfied with that, and I patted him on the head, and put my hand to his mouth and allowed him to lick it ; he also allowed me to examine the foot which I had hurt so much while operating upon himthus carrying out to the most minute particular the character given of the gentle tiger until he came into contact with civilisation, given by Martial : "Lambere securi dextram consueta magistri."

It is impossible for me to go into all the details ; they must be left for future dovelopment; brat I will say in brief that the principle of least action, when applied to the limbs of a tiger, require two conditions-one in the fore paw, and the other in the hind limb. In an action such as the tiger makes with the back stroke of the paw of the fore-limb, we have combined groups of muscles acting upon the arm and the fore-arm ; and it is easy to prove by the principle of least action that when the resultant of the great muscles, the latissimus dorsi and the teres major, that act upon the arm, becomes perpendicular to the humerus, at the same moment of time the triceps muscle must be perpendicular to the line joining the olecranon process of the ulna with the centre of the elbow-joint. The most powerful stroke that the arm of a strong man can give is the back-stroke, as every swordsman knows. The back-stroke of a guardsman will cut a leg of mutton in two. The back-stroke in rackets is much more powerful than the direct stroke. It is made by bringing the muscles of the fore-arm and the humerus into co-ordination. All the efforts of the racket-player and the swordsman would not produce this effect unless the law were followed, that these two angles which have no connection with each other passed through ninety degrees together. We have, then, the very curious fact that the principle of least action in a tiger's fore-paw or arm requires that these two angles, which have no relation to each other, varying in magnitude at every moment, must, to produce the maximum effect, pass through ninety degrees at the same moment; and we find that Nature accepts the consequence. I know no animal in which this law is not carried out, and a corresponding law to which $I$ shall now call attention in the hind-leg. In the hind leg the line O...sart (Fig. 7) joining the centre of the hip-joint with the tuber ischii, becomes at right angles to the resultant of this biceps femoris muscle, whether triangular or prismatic, at the same moment that the muscles of the calf (G B) become perpendicular to the line (B Y) which is drawn through the centre of the ankle-joint. In the case of the hind-leg the arrangement skips a joint. In the fore-arm the shoulder is related in this remarkable manner to the elbow-joint. In the hind-leg the hip-joint is not related to the knee-joint, but to the heel; and those two angles, which have no necessary relation whatever to each other, made by one group of forces at the hip. joint, and another group of forces quite distinct from them at the heel, pass through ninety degrees together-one of the most remarkable instances on record of the skill, contrivance, and foresight, with which the frame of animals has been constructed.

You have seen on board a large steamship an engineer with a little can of oil in his hand putting his head in among moving bars of iron, poking his can of oil among little joints; and you feel conscious that if you attempted to do it you would lose your life. That man knows to the tenth of an inch the motion of every bar-when it comes, when it retreats, when it comes forward again; he knows that he can rely upon the motions of the bars with certainty to the hundredth part of an inch. When we see these motions regulated by the intelligence of the engineer who contrived the machine, describing their angles, and passing through each angle at the exact moment the engineer intended, no person is fool enough to believe that there is not contrivance and design. I am ashamed to say there are intelligent men who can look upon similar structures more wonderful in contrivance in the world of nature, and not recognise the hand of Him who made them.

Before parting with this subject, I may be allowed to give a word of advice to some of those who hear me. I have shown you that these two angles pass through ninety degrees together; therefore, any arrangement of an artificial kind that interferes with the angles passing through ninety degrees together would be most injurious. I am told that it is now the habit, or has been the habit, of ladies in Americaperhaps in this country - to wear high-heeled boots for the purpose of producing the Grecian bend. I am not acquainted with the subject, but the ladies present will know whether this be the fact. I would caution you against the practice. You shorten, by high-heeled boots, the distance between the points $\mathrm{B}$ and $\mathrm{G}$; you prevent, therefore, the beautiful play of angles and joints from coming into effect, and you sacrifice in the movement of the limb what you gain in supposed grace of figure. If the practice continue, I should expect that our young ladies of some future period, with the bright colours of their heads and the development of the tendons in their feet, will present an appearance not unlike the flamingos that strut about the gardens in Regent's Park.

I now come to my last and most interesting application in this lecture of the principle of least action. I have shown that a quadrilateral muscle becomes occasionally a skew muscle, like the skew bridge known to engineers. . Every line in it is straight, but the whole forms a curved surface, and any plane drawn across that surface would give me a conic section. (Fig. 6.) I come now to the great pectoral muscle in the wing of the bird. I have before me two diagrams that have cost me many hours of hard work. One of them represents the wing of the albatross (Fig. 8). Here is the socket, s, or, as anatomists

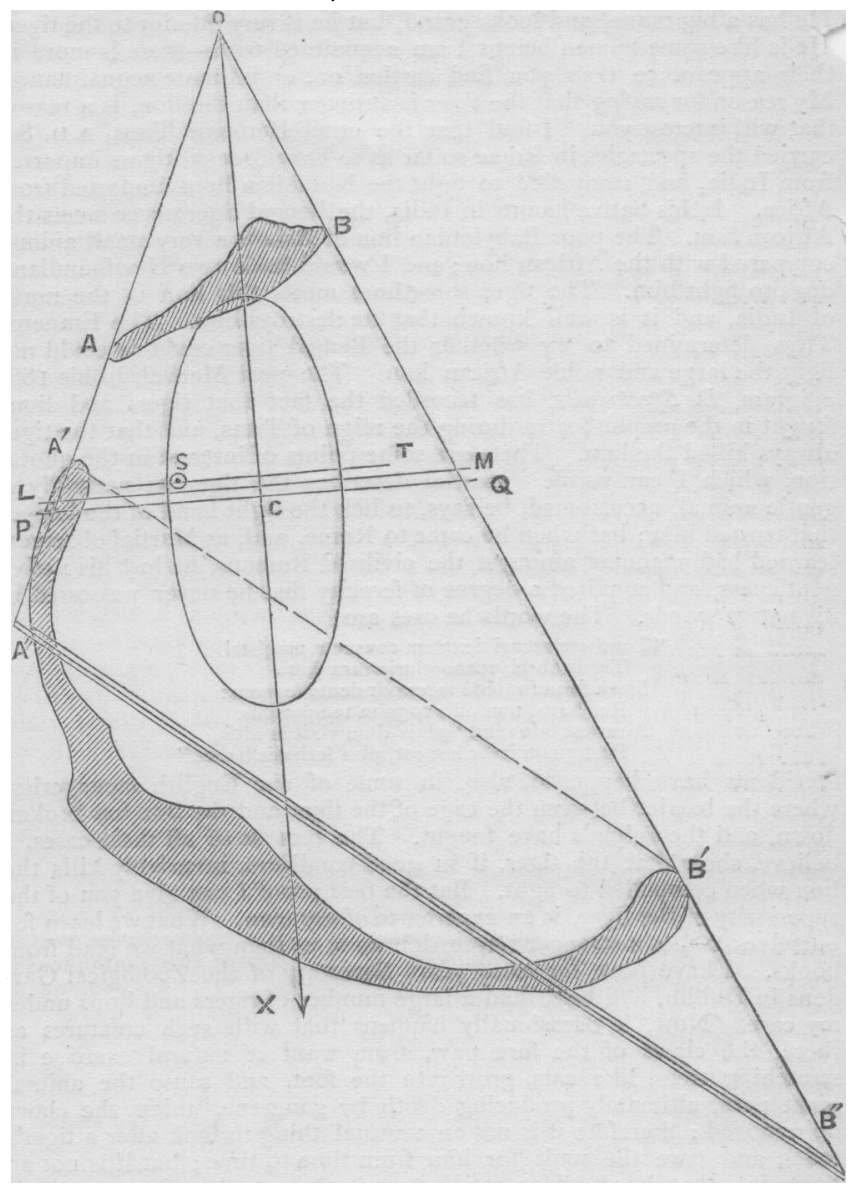

Fig. 8.

call it, the glenoid cavity, of the wing ; $A^{\prime} A^{\prime \prime}$ is the furcular clavicle : $A^{\prime \prime} B^{\prime}$ is the sternum; this curved line, $A^{\prime} B^{\prime}$, represents the origin of the great pectoral muscle; and A $B$ is the insertion of the pectoral muscle into the humerus, placed so that this insertion shat occupy the same plane as the origin of the muscle. I believed that 
I had succeeded in carrying the principle of least action to such a point that I should be able to make a prediction. And here I would call your attention to the important fact that no science whatever is worthy of the name, no science is anything but a collection of facts, which is not able to predict consequences-when certain facts are given, to predict other facts ; and in proportion as any science possesses the high prerogative of being in a condition to predict from a certain number of conditions other conditions, it deserves the name of an exact science. In other words, it has come under the control of geometry, the great queen and mistress of all sciences. I selected for the purpose of prediction the wing of the bird, and I said to myself, "I can trace accurately the origin of this great muscle, I know its insertion, and I will try and predict an unknown thing about it; viz., the position of its axis of rotation." Let $A^{\prime} B^{\prime}$ be any curve whatever olsserved in Nature, as the origin of the pectoral muscle of a bird; let $A B$ be any other curve observed in Nature representing the insertion of the muscle in the arm. Then draw A'A B'B to meet in $O$. Given these two curves, I was able to draw the bisector of the angle AO B. I was also able to draw a certain right line, such as $\mathrm{PQ}$ or $\mathrm{LM}$, at right angles with that bisector, and to say, if the muscle of the bird, which is a skew quadrilateral muscle, contracts so as to produce the maximum advantage that it can produce, the axis of rotation round which the wing of the bird must turn will be a particular line that I can calculate. I shall not trouble you with the details of the calculation; they would be very uninteresting to an audience like this. You will possibly see the importance of them when I tell you that they consist in finding a certain ellipse-the ideal ellipse as it exists in the albatross I have drawn. There is an elliptical curve which is to be calculated, and I say that the minor axis of that ellipse is the axis of the greatest effect, or the axis of least action round which the wing of the bird revolves. The black axis $\mathrm{S} T$ represented on the diagravi is the actual observed axis as I have found it in the wing of the albatross ; and the red axes, such as $P Q$ and $L M$, represent the axes found by me by successive approximations, each coming nearer and nearer to the real axis. I chose the albatross for the following reason. Just as I believe the tiger to be the most worthy object of study in considering the question of the arrangement of the limbs of quadrupeds, from its great strength and size and activity, so I believe the albatross to be the most wonderful of all birds with which we are acquainted, and to be worthy of study. Its habits have been described by Portuguese navigators ; and they have been described by Coleridge in the beautiful poem The Ancient Mariner. The albatross possesses very remarkable peculiarities. He seldom or never flaps his wing, but his soaring power in the air is prodigious. When he has once attained a certain height, he is so beautifully constructed that he is able to keep that height, or at least to lose less of it than any other known bird. The only other bird in the world to compare for a moment with the albatross in the power of soaring is the condor vulture. I have here a drawing of the wing of the condor vulture and the wing of the albatross. Any one looking at the diagram will see that, if I took a pair of shears and cut off the white feathers from the wing of the vulture, I should reduce it to the wing of the albatross. This was my main reason for choosing the wing of the albatross as a type of the perfection of flying. I studied the wings of the eagle, the hawk, the vulture, and other birds ; and I found there was a sort of type underlying them which corresponded with the wing of the albatross. I can demonstrate, but will not trouble you with the demonstration now, that the albatross wing contains all the conditions for merely soaring. It sleeps upon the water at night; it feeds upon small floating molluscs and crustaceans which it finds in the sea, or gladly accepts from passing sailors pieces of biscuit offered from the ships. When morning comes, the albatross rises slowly and laboriously from the water. $\mathrm{He}$ is described by the ancient Portuguese sailors as running upon the sea, because he rises so slowly in the air that for nearly half a mile he attempts to rise from the surface, and his feet touch the waves. Slowly and painfully our poor bird rises to a height of about a thousand feet, and he seems content with this thousand feet; he has the power of losing as little of it as any known bird. If a ship be in sight, the albatross follows the ship; but, if no ship be in sight, he is cunning enough to look out for another albatross that sees a ship. If he sees another albatross at a distance moving in a particular direction, he knows that it sees a ship, or sees an albatross that sees an albatross that sees a ship; and so, before ten o'clock in the morning, the ship is surrounded with flying albatrosses, soaring most gracefully in the air. Woe betide the sailor that shoots an albatross! I was five years in obtaining this creature for dissection. Through Mr. Moore, the curator of the Museum in Liverpool, I was put in communication with a number of sea-captains going round Cape Horn. They told me that there was great superstition among the sailors about the albatross. They all remembered the story of the Ancient Mariner, and the passage into the " silent sea", where "slimy things with legs did crawl". You remember Coleridge's words about the bird and the prejudices connected with it.

$$
\begin{aligned}
& \text { "And the good south wind still blew behind, } \\
& \text { But no sweet bird did follow', } \\
& \text { Nor any day for food or play } \\
& \text { Came to the mariner's hollo! } \\
& \text { "And I had done a hellish thing, } \\
& \text { And it would work 'em woe: } \\
& \text { For all averred I had killed the bird } \\
& \text { That made the breeze to blow." }
\end{aligned}
$$

In spite of these difficulties, I obtained my albatross, and made my calculation. I was an hour dissecting the pectoral muscle, another hour making measurements upon it, and another hour transferring those measurements to paper for further measurement. After that was done, it cost me five hours of incessant labour with logarithmic tables to take out the figures and calculate the red line $P Q$, which represents my first approximation; and the second approximation, $L \mathbf{M}$, required ten hours of numerical work. I have applied equal labour to every one of these six birds; viz., albatross, grebe, macaw, wood-pigeon, pheasant, and heron. My calculated red line represents what I believed would be the position of the axis of the wing corresponding with the law of least action. It comes, in every case, as you observe, uncommonly close to the black axis, $\mathbf{S T}$; it is sometimes above it, and sometimes below. It presents no suspicious nearness to the black axis, and there is a characteristic about it that I must ask your permission for two minutes to dilate upon. It is a characteristic of every real discovery that, if we make closer and closer approximations, we shall find nearer results to the true, but we shall always find certain residual phenomena left behind which our theory will not explain. Now, in this case of the vulture I have a residual phenomenon. The vulture has not only to soar like the albatross, but he has to possess a power which the albatross does not, of rising in the air in the course of an hour or two, from the level of the Pacific Ocean to the heights of Cotopaxi. He has, therefore, two problems to solve; he has to soar, and rise to a height rapidly. There is hardly any other bird in which, if we studied their habits, we should not find that there were two or three objects to accomplish with their wings. In this calculation, I have entirely neglected those subsidiary objects ; but in the case of one or two birds like the vulture, where I have made the calculation and brought in the two conditions, I have succeeded in producing the red axis of my ellipse so as to become identical with the black axis, S r. Hence, whether we take into account the other objects which wings may have to accomplish, or the necessary errors of observation, because the black line itself is only an observed line, and a line observed after death, I have reason to believe that I have succeeded in showing that we possess a power of prediction with regard to the wings of birds, and to other principles of animal mechanics, that entitles us to say that that science of animal mechanics has entered into the class or group of exact sciences.

In conclusion, I wouid say, with regard to prediction, you are all acquainted with the planet Neptune. IIn fact, the poor planet Neptune is used up; he has been so hackneyed a subject for lecturers and audiences that I will not say anything about him. My friend Professor Tyndall has made most of you acquainted with the extraordinary prediction of conical refraction by Sir William Hamilton, whose name will be remembered by those who come after us as that of the greatest mathematician of the nineteenth century. I shall not trouble you with his theory of conical refraction, except to mention a story that possesses an interest as coming from the lips of Sir William Hamilton himself. He told me that he made the calculation late at night. He was not an experimenter, and, as you are aware, the present distinguished Provost of Trinity College, Dr. Lloyd, was the man who actually saw conical refraction first. When Sir William Hamilton took his scribbled paper to Dr. Lloyd, and asked him to make the experiment, any person, not a mathematician (Sir William Hamilton told me), and not accus. tomed to reading his marks, made on little scraps of paper, the backs of letters and the like, would have said, " $\mathrm{Oh}$, he is taking to his friend a piece of paper on which, for fun, he has allowed a spider that he has dipped in ink to run about."

We find, then, nothing tentative in any branch of Nature. There is nothing tentative in astronomy. No planet ever seeks to move more perfectly in its orbit; it does so from the beginning. We have no evidence that light describes its path by a succession of attempts; it is singly, doubly, or conically refracted, according to fixed conditions, and has all the appearance of having been always so. The socket and the axis round which birds' wings revolve are placed exactly in the position best suited to produce the best effect; and here again I find no tentative process. There is no evidence in Nature of birds with imperfect wings; no proof of a succession of blunders before perfection was attained. Al 
is perfect; and all was always perfect. There have been no " tentative miracles" in nature, no failures, nor trials. The graceful limbs of the beautiful tiger and the expanded pinions of the sweet albatross of Coleridge speak to the ear of reason in language that cannot be misunderstood,

"The hand that made us is Divine."

\section{E C T UR E}

ON

N A T I O N A H E A L T H.

DELIVERED AT

The Royal College of Physicians of England.

BY

HENRY W. ACLANU, M.D., D.C.L., F.R.S., Regius Professor of Medicine in the University of Oxford.

\section{I. - The Foundations of National Health.}

No subject has received more impulse in this country within the last twenty-five years than the prevention of disease. We are ripe for comprehensive legislation. Mr. Göschen, taking a wide view of the question, has already embodied in a Bill provisions by which the relations of a large proportion of the medical profession to the public may be changed, and a new conception of the functions of medical men may be introduced into every corner of the country.

Though the exigencies of political affairs have forced the withdrawal of this Bill for the moment, I shall endeavour, in the observations which I am about to make, to sketch the intricate bearings of a subject of no small moment, from the point which seems to offer the fullest conception of the groundwork of national health. But I admit the all but impossibility of the task within the limits assigned to an ordinary lecture.

If there be a national health as distinguished from personal health, it is a problem of the last importance to know by what laws the standard of national health is raised, by what it is depressed. If national health be intimately connected with national virtue, and both with national prosperity -if all have their foundations in the very conditions of human life on the earth--then it will seem probable that national vice will be found linked with physical weakness and general decline, by the same correlative necessity.

These laws of our being are the expression of the fact, that nations, like individuals, placed in given conditions, must act within certain limits-limits admitted by all, whether they believe them to be bounded by the possible combinations of chance, or assigned by the intelligence of a Superior Will. National habits, good or bad; national licence and national self-restraint ; national vice and national piety; national vigour or national indolence; are propagated through the individuals of which the nation is composed-being attached to individual character, and handed on from generation to generation, modified however by individual education, or those great catastrophes which, like subsoiling in a barren land, bring about fresh combinations, and give birth to products good or bad, better or worse, as the laws, moral and physical, which regulate the combination, may compel.

It may be alleged against these fundamental conceptions that national health is a fiction of the mind-that no such collective physical condition exists. The objection would be one of words. Family constitution and hereditary taint certainly exist ; and a multitude of individuals forming one army may, by the operation of moral causes, go anywhere and do anything, or may be without power, without will, without hope.

We must not stop to discuss in full by what subtle links families are bound into peoples, peoples into races; but, limiting our view to our own immediate nation, which may serve as an instance for all, consider briefly how the physical condition of our people has been attained, and by what means it may be preserved or improved - our national health, in short, What is it? and, What are the duties of the State towards it?

The health of an individual is the balanced condition of organs best fitted for due performance of the functions of body and mind within the capacity of the individual. The national health is that condition of the individuals of the nation which enables the individuals of the nation to discharge rightly their respective functions in the state- "to do their duty in the state of life to which they are called"; the statesman to be in training for exercising the complex intellectual operations of his high office; the artisan, the soldier, the abstract thinker, each for his ; and if we regard the philosophic teaching of the great author of the Republic, parents of either sex, for the raising of the future citizens for the state (The Republic of Plato, Book iv).

The sole question which here seems open to cavil is, How far we can influence national health in the wide sense just hinted at? Can the abstract speculations of the Republic bear practical fruit? Can we in. fluence all the factors which are contained in the elements of national health? Let us see what they are.

Take any given Englishman. What is his descent-Roman, Norman, Saxon, Dane, French ? What influences have operated on him since his progenitors were among the number of workers in flint or in bone, or in bronze? Did they become farmers, warriors, chiefs ? intellectually accustomed to command or to obey? physically to endure or to shrink? morally thrifty, contented, peaceful or turbulent, drunkards and dissolute? Were they in later times exposed to the diseases of hot climates? Were any syphilitic? Did they intermarry in close relationship, or seek far a-field the partners of their lives? What would be the qualities which, like the now famous Black Bar of the Rock Pigeon, might reappear on their scutcheons-pride, pugnacity, syphilis, gout, phthisis? Terrible questions these which the third and fourth generations ask of the sins of their forefathers and of their own. There is much to be said for the squire who never passed the picture of his great-grandfather but he shook his stick at him with an oath, and said, "Your drink brought gout down upon us all"..*

Philosophically, indeed, this most anxious inquiry might, we now know, be pursued, and is being, with rare practical discernment, pursued into the very origin of our race. But I forbear, in a question of great practical import, to do more than remark, that Darwin's discussion has a direct bearing on the conception of national health. It tends to confirm the conviction that acquired habits, whether of body or mind, may be very permanent in a race. That acquired increments for good may be permanent for good we cannot doubt, with the qualification that they must be maintained by each individual of each generation. The potential good being inherited, may, by moral or physical struggle, be retained, and the potential evil be to some extent eradicated. But in every case we must believe that the inherited good attained, perhaps by generations of valour or virtue, may be in a moment shattered like some lovely work of fictile art that was produced only after years of education and months of applied skill.

These general reflections bear mainly on bodily characters, but not wholly so. A woof of mind runs through the web of all animal organisation; and the view we take of the elements of national health is coloured by our conception of the respective relations of body and spirit. When we look abroad on the animal world, we perceive such union of mental and bodily functions, that we are at a loss to say whether the matter, of which the organism is composed, and by which alone the bundle of mental qualities which it possesses can operate in the world, is primarily set in motion by mind, or is itself the primum mobile, the basis and very essence of mind. The difficulty of solving this question, so fundamental to all speculation on the organised world, has increased with time; and so the principles on which the education of man shall be conducted have become a subject of yet keener debate. He who believes that we are but what we see, and handle, and measure, and weigh; he who looks not beyond the present chemical concurrence of some half-hundred elements, combined within themselves; and he who says in his heart "There is no God"; all these can look on education and on health as problems only of physical science, to be settled by material measures. But, without pursuing a subject far too long for our present opportunity, let it be said that this hard material view which has once and again cropped up in history, since culture and literature began, cannot be accepted as other than an hypothesis for settling the insoluble problem of the nature of man and his co-tenants of our planet. Look out and see every spot of earth, of water, of air, occupied by beings fitted, if you will, for their place by natural selection; adorned, if you please, by the sexual impulse to display ; and what do you find ?-material organism fitted to perform certain material functions, bundles of mental powers fitted to put that adapted machinery in operation. Machinery and mind are alike inherited ; their qualities improvable, and transmitted; the temper, so to say, of progenitors lost and reappearing. Shall any one presume to say that as yet the genesis or pangenesis of this complicated organisa. tion of earth is so known to him that he can declare that matter alone

* The Chinese have very strict notions as to hereditary taint; chiefly, however, on moral grounds. The children of actors, among others, for three generations are excluded from the greatest privileges of citizenship, and capital punishments may follow unlawful attempts to exercise them. Not long since, thirty examiners in cluding an ex-Chancellor, were put to death for admitting an actor to a competitive examination. 